\title{
A Novel Anastomosis after Ilecolic Resection for Crohn's Disease
}

\section{Gaetano Luglio}

Federico II University of Naples, Department of Clinical Medicine and Surgery, Naples, Italy

Crohn's Disease (CD) is well-know idiopathic inflammatory bowel disease,characterised by a transmuralinflammation which can virtually affect all the gastrointestinaltract. Its true aetiology is basically ignored and a causal therapy is not possible to date; the most peculiar aspect of CD certainly lies in its absolute heterogeneity, as we might face lots of different scenarios, locations of the disease, pathologic behaviours and severity of the disease itself.

For these reasons, the cornerstone for the treatment of $\mathrm{CD}$ lies in a complex, multimodal management, requiring the close collaborations among surgeons,gastroenterologists, radiologists and staff nurses.

Advances in surgical and medical therapy are in someway changing the course of the disease. Novel surgical techniques, laparoscopy, better recovery pathways and new frontiers in medical therapy allow nowadays to deal with complex and recurrent scenarios, trying to spare bowel and anal function, thus ensuring the patients a better quality of life.

One of the challenge surgeons and gastroenterologists involved in the treatment of CD need to deal with, is the risk for recurrences. Data from postoperative endoscopic follow-up show that in absence of medical treatment the endoscopic recurrence rate may reach $80-100 \%$ in 3 years after surgery; clinical recurrence rate is $20-25 \%$ / year instead [1]. Despite the significant advances in medical therapy, the fact that most of recurrences appear at the anastomotic site, emphasise how surgery itself might have a causative role. Different ileocolic anastomotic configuration have been described, but a clear benefit in terms of recurrence prevention has not been demonstrated to date. ECCO guidelines [2] support the use of a stapled side-toside anastomosis after ileocolic resection as the technique of choice. Most of recurrences appear just proximal to the anastomosis and this has led to the idea that anastomotic configuration and subsequent faecal stasis may play a role. On the other hand, a clear advantage of stapled side-to-side anastomosis in preventing recurrence has never been demonstrated before and the recommendation basically lies on the results of two metaanalysis demonstrating an advantage of sideto-side anastomosis in reducing anastomotic leak over end-to-end anastomosis [3,4]; other studies, however, did not reach the same conclusion [5].

A novel anastomotic configuration has been described by Kono et al. in 2011 [6], combining stapled and hand-sewn anti-mesenteric functional end-to-end anastomosis (Kono-S anastomosis) in order to reduce surgical recurrence. From a technical point of view, the anastomosis is performed cutting the ileal and the colonic edge with a linear cutter, locating the mesentery at the centre of the stump, perpendicular to the staple line.

The bowel needs to be cut really close to the bowel wall in order to minimise any devascularisation or denervation. The two staple-line are then approximated with interrupted stitches in order to create a kindof supporting column to prevent any further anastomotic distortion. The anastomosis itself is then created, performing two longitudinal enterotomies, $7 \mathrm{~cm}$ long, at the anti-mesenteric side, which are then re-approximated in one or two layer in a transverse fashion.

\author{
Publication History: \\ Received: September 11, 2017 \\ Accepted: October 09, 2017 \\ Published: October 11, 2017

\section{Keywords:} \\ Crohn's Disease, Anastomosis, Medical therapy, Laparoscopy, \\ Endoscopy
}

As previously mentioned, anastomotic configuration is supposed to be responsible for faecal stasis, bacterial overgrowth and bowel perfusion; a wide lumen stapled side-to-side anastomosis was thought to reduce faecal stasis, thus reducing the risk for recurrence; however, this has never been demonstrated. In their study, Kono et al. [6] report excellent results in a group of 69 patients who underwent novel Kono-S anastomosis between 2003-2009, compared with an historical group of 73 patients, receiving conventional anastomosis.

They found that the median endoscopic recurrence score was significantly lower in the Kono-S group, with a subsequent reduced risk of surgical recurrences ( $0 \%$ vs $15 \%, \mathrm{p}<0.0013$ ). The mechanism of the anastomosis in reducing the risk for recurrence deserves some attention from our standpoint: 1 . The anastomosis itself, being constructing in a transverse fashion, similarly to a strictureplasty, creates a large lumen 2 . The staple lines, on the back of the anastomosis, create a supporting column to prevent anastomotic distortion in case of recurrence, so that the risk of stenosis associated with recurrent disease is lower; 3 . More interestingly, the possibility to exclude the mesentery from the anastomosis lumen. It has been demonstrated that CD always appears and recurs at the mesenteric side [7], which is hidden on the back of Kono-S anastomosis at the centre of the supporting column. Additional advantages of this anastomosis is the maximum preservation of blood supply and innervation, which are both supposed to be factor associated with recurrence in CD.

A larger multicentre series also including an Institution from USA has also been recently published with the same interesting results [8, 9]. A randomized controlled trial is also currently ongoing in our Institutions, comparing the Kono-S anastomosis vs the standard side-to-side anastomosis and has been registered on ClinicalTrial. gov (NCT02631967). Apart from the encouraging result obtained in a patient with a severe, multirecurrent $\mathrm{CD}$, that has not recurred againafter Kono-S anastomosis to date [10], preliminary results on our series seem to be very promising too and have also been presented at the last ECCO meeting in Amsterdam [11].

"Corresponding Author: Dr. Gaetano Luglio, Federico II University of Naples, Department of Clinical Medicine and Surgery, Naples, Italy; E-mail: gaetano.luglio@gmail.com

Citation: Luglio G (2017) A Novel Anastomosis after llecolic Resection for Crohn's Disease. Int J Surgical Porced 2: 124. https://doi.org/10.15344/2456$4443 / 2017 / 124$

Copyright: ( 2017 Luglio. This is an open-access article distributed under the terms of the Creative Commons Attribution License, which permits unrestricted use, distribution, and reproduction in any medium, provided the original author and source are credited. 
Citation: Luglio G (2017) A Novel Anastomosis after Ilecolic Resection for Crohn's Disease. Int J Surgical Porced 2:124. https://doi.org/10.15344/2456$4443 / 2017 / 124$

\section{Competing Interests}

The authors declare that they have no competing interests.

\section{References}

1. Van Assche G, Dignass A, Reinisch W, van der Woude CJ, Sturm A, et al (2010) The second European evidence-based Consensus on the diagnosis and management of Crohn's disease: Special situations. J Crohns Colitis 4: 63-101.

2. Dignass A, Van Assche G, Lindsay JO, Lémann $M$, Söderholm J, et al. (2010) The second European evidence-based Consensus on the diagnosis and management of Crohn's disease: Current management. J Crohns Colitis 4: 28-62.

3. Simillis C, Purkayastha S, Yamamoto T,Strong SA, Darzi AW et al. (2007) A meta-analysis comparing conventional end-to-end anastomosis vs. other anastomotic configurations after resection in Crohn's disease. Dis Colon Rectum 50 :1674-87.

4. He X, Chen Z, Huang J, Lian L, Rouniyar S, et al. (2014) Stapled side-toside anastomosis might be better than handsewn end-to-end anastomosis in ileocolic resection for Crohn's disease: a metaanalysis. Dig Dis Sci 59 :1544-51.

5. Scarpa M, Angriman I, Barollo M, Polese L, Ruffolo C, et al. (2004) Role of stapled and hand-sewn anastomoses in recurrence of Crohn's disease. Hepatogastroenterology $51: 1053-7$.

6. Kono T, Ashida T, Ebisawa Y, Chisato N, Okamoto K, et al. (2011) A new antimesenteric functional end-to-end han dsewn anastomosis: surgical prevention of anastomotic recurrence in Crohn's disease. Dis Colon Rectum 54 :586-92.

7. Anthony A, Dhillon AP, Pounder RE, Wakefield AJ. (1997) Ulceration of the ileum in Crohn's disease: correlation with vascular anatomy. J Clin Pathol $50: 1013-7$.

8. Kono T, Fichera A, Maeda K, Sakai Y, Ohge H, et al. (2016) Kono-S Anastomosis for Surgical Prophylaxis of Anastomotic Recurrence in Crohn's Disease: an International Multicenter Study. J Gastrointest Surg 2016;20:783-90.

9. Kono T, Fichera A.(2014) Kono-S anastomosis for Crohn's disease: narrative - a video vignette. Colorectal Dis 16:833.

10. Luglio G, Rispo A, Castiglione F, Imperatore N, Giglio MC, et al. (2016) Kono-type anastomosis in a patient with severe multi-recurrent Crohn's disease. Int J Colorectal Dis 31:1565-6.

11. Luglio G, Rispo A, Peltrini R, Sacco M, Sollazzo V, Bucci C, et al. (2016) SuPREMe-CD Study: surgical prevention of anastomotic recurrence by excluding mesentery in Crohn's disease-preliminary results and trial protocol. Journal of Crohns \& Colitis 10: S398-S398. 